\title{
A PRÁTICA DISCENTE NA CONST RUÇÃO DO CONHECIMENTO SOBRE O FENÔMENO DAS DROGAS
}

\author{
Vanessa Oliveira G uimarães dos SANT OS ${ }^{b}$, O ctavio M uniz da Costa VA RGE N Sc
}

\section{RESUMO}

T rata-se de uma pesquisa descritiva com abordagem qualitativa, desenvolvida com estudantes de graduação em enfermagem da U niversidade do E stado do Rio de Janeiro (U E RJ ). Teve como objetivo discutir as ações vivenciadas e a prática social efetivada pelos acadêmicos no atendimento a usuários de drogas. Os dados foram coletados de dezembro de 2008 a janeiro de 2009, utilizando-se grupos focais constituídos por 19 acadêmicos dos três últimos semestres do curso. 0 projeto foi aprovado pela Comissão de Ética em Pesquisa da UERJ e os participantes assinaram o Termo de Consentimento Livre e Esclarecido. Os resultados evidenciar am a dificul dade discente no enfrentamento da realidade, decorrente do contraste entre teoria e prática, apontando como dificuldade decorrente da condução docente inapropriada. Conclui-se que as instituições de ensino devem otimizar a utilização do processo de ensinagem. A formação dos profissionais, relacionada ao fenômeno das drogas, mostra-se essencial por ser cada vez mais freqüente no cotidiano.

Descritores: Estudantes de enfermagem. Ensino. U suários de drogas.

\section{RESUMEN}

Investigación descriptiva, cualitativa, cumplida con estudiantes de pregrado en enfermnería de la U niversidad del E stado de Rio de J anei ro, B rasil. $O$ bjeti vó di scutir las acciones y la práctica social vivi das por los estudiantes durantela asi stencia a usuarios dedrogas. $L$ OS datos fueron obtenidos de D ici embre de 2008 a E nero de 2009, se usaron grupos focal es constituidos por 19 académicos de los últimos tres semestres del curso. E I proyecto fue aprobado por la Comisión É tica en Investigación. Todos los participantes firmaron el Consentimiento Informado. L os resul tados evi denciar on la dificultad de los estudiantes mi entras enfrentaron la realidad, debido al contraste entre teoría y práctica, señalando tal dificul tad como consecuencia de un abordaje educativo inapropiado. Se concluye que las instituciones de enseñanza deben optimizar el uso del proceso de "enseñar". L a formación de profesionales está considerada esencial por ser cada vez más frecuente en la práctica diaria.

Descriptores: E studiantes de enfermería. E nseñanza. Consumidores de drogas.

Título: $\mathrm{L}$ a práctica de los estudiantes en la construción de conocimiento sobre el fenómeno de drogas.

\section{ABST RACT}

This is a qualitative descriptive research, carried out with nursing undergraduates from R io de J aneiro State U niversity, B razil. The purpose is to discuss students' experiences and their social practice in assisting drugs users. D ata were coll ected from D ecember, 2008 to J anuary, 2009, with the use of focal groups composed by 19 undergraduates from the last three semesters of the course. The project was approved by the E thics R esearch Commission. All participants signed the Informed Consent. T he results evidenced students' difficulty in facing reality, due to the contrast betw een theor $y$ and practice Such difficulty came out as a consequence of an inapropriate educational approach. We concluded that the academic institutions should optimize the use of teaching process. P rofessional formation related to the phenomenon of drug abuse is considered essential as it becomes more and more frequent in nurses' daily routines.

Descriptors: U ndergraduates, nursing. T eaching. D rug users.

Title: Students' practice in the construction of knowledge about the phenomenon of drug abuse

\footnotetext{
a $O$ presente artigo consiste em análise de resultados parciais da dissertação de M estrado apresentada em 2010 à $F$ aculdade de E nfer magem da U niver sidade do Estado do Rio de Janeiro (UERJ).

b M estre em E nfermagem pelo Programa de Pós-G raduação em Enfermagem da UERJ, Líder da E quipe de Enfermagem na Casa de Saúde São José, Rio de Janeiro, Brasil.

'D outor em E nfermagem, Professor T itular da Faculdade de E nfermagem da UERJ, Coordenador do N úcleo de E studos e Pesquisas E nfermagem, M ulher, Saúde e Sociedade (NE PEN -M U SAS), Líder do Grupo de Pesquisas sobre G ênero Poder e Violência na Saúde e na Enfermagem, Rio de Janeiro, Brasil.
} 


\section{INT RODUÇÃO}

Esse estudo traz discussões sobre a abordagem do fenômeno das drogas no meio acadêmico, em especial na F aculdade de E nfermagem (F E N F ) da U niversidade do Estado do Rio de Janeiro (UERJ ), Rio de Janeiro. Consiste em anál ise de resultados parciais da pesquisa intitulada "A construção do conhecimento acerca do fenômeno das drogas: a experiência da Faculdade de Enfermagem da UERJ ${ }^{\prime \prime(1)}$. Tem como objeto as experiências vivenciadas pelos discentes frente aos usuários de drogas.

Entende-se por droga qualquer substância que modifica as funções do organismo, sendo a droga psicoativa capaz de ocasionar al ter ações fisiológicas ou comportamentais, alterando o psiquismo. São classificadas de acordo com suas ações no sistema nervoso central: depressoras, estimulantes e perturbadoras ${ }^{(2)}$.

A mplamente discutido no cenário mundial atual, o uso e abuso de drogas éum assunto de grande dimensão e com incidência assustadora. É estimada pela Organização M undial de Saúde a existência de 185 milhões de usuários de drogas ilícitas, aos quais se juntam 2 bilhões que fazem uso de álcool e 1,3 bilhões de tabaco, configurando um problema de saúde pública(3). Como podemos nos deparar com usuários de drogas em todos os níveis de assistência do setor da saúde e em todas as especialidades, faz-se necessária a qualificação do enfer meiro para atuar no cuidado a essa clientela. A ssim "a enfermagem ganha uma nova responsabilidade: aprender ou/ e aperfeiçoar a abordagem a esse público, promovendo e prevenindo esse uso buscando mudar a realidade vigente"(4).

Entretanto, muitos destes profissionais não encaram o uso e abuso de drogas como patologia, levando em conta conceitos pré-concebidos acerca deste indivíduo que sofre com a dependência química. T al afirmação leva à reflexão sobre a formação profissional dos enfermeiros, que é apontada em um estudo sobre a atuação docente na prevenção do uso de drogas como defasada, resultando em conhecimentos superficiais sobre a temática(5).

Então, durante sua graduação, o estudante deve adquirir e desenvolver as competências necessárias ao exercício da profissão, estando apto a atuar na redução da demanda das drogas e no cuidado dos seres humanos envolvidos neste contexto(6).
A fim de exercer a profissão cuja essência consiste no cuidar, o enfermeiro protagoniza o papel de educador em saúde, devendo de qualquer preconceito para que a assistência a essa clientela seja eficaz e essencialmente humana ${ }^{(7)}$.

Dessa for ma, as instituições de ensino superior devem se preocupar com a qualidade dos resultados do seu ensino, que se traduzirá numa preparação mais condizente com as necessidades atuais dos discentes, futuros enfermeiros, considerando a importância da preparação político-pedagógica de seus docentes ${ }^{(8)}$. Para tanto, é utilizado 0 processo de ensino-aprendizagem, que consiste no manejo de fatores diversos e de sua aplicação de forma planejada ou sistemática, onde os discentes vão se transformando em sujeitos da construção e reconstrução do saber ensinado, juntamente com o docente, que também é consider ado sujeito desse processo $^{(9)}$.

A ssim sendo, o objetivo desse artigo consiste em discutir as ações vivenciadas e a prática social efetivada pelos acadêmicos de enfer magem da FENF/ UERJ no atendimento a usuários de drogas.

\section{REFERENCIAL TEÓRICO}

Existem dois tipos de educação: bancária e problematizadora. A primeira tem como base a experiência do professor e a transmissão desse conhecimento. A segunda implica em situações-problema expostas pelo professor aos al unos, que tem participação ativa nesse processo ${ }^{(9)}$. Como aprender é um processo dinâmico, onde 0 aluno mobiliza suas atividades mentais para compreender a realidade que o cerca, analisá-la e, depois, modificá-la $a^{(10)}$, este estudo tem como base a educação problematizadora. E sse model o educacional é proposto no projeto político-pedagógico da F E N F / U ERJ , cenário do estudo.

"A fim de alcançar o objetivo proposto, o projeto pedagógico deve considerar a necessidades da sociedade contemporânea, formando cidadãos capazes de buscar soluções para os problemas societários"(11). A ssim, o currículo deveexpressar os compromissos com a educação, com os futuros enfermeiros e com a política pública de saúde para a população e seus princípios de acessibilidade, de univer salidade, de equidade e integ ralidade ${ }^{(12)}$.

0 modelo tradicional de ensino-aprendizagem ainda é bastante presente na sociedade. $M$ uitos 
docentes e discentes foram formados pela pedagogia bancária, onde o foco é o conteúdo, dificultando a ruptura e a superação desse modelo. Assim, o docente depara-se com o desafio de formar profissionais de modo difer ente daquel a em que ele próprio foi formado ${ }^{(13)}$. O u seja, assumir o papel de educador, facilitador do processo de aprendizagem, rompendo com o modelo responsável pela mera transmissão de informações, sem compromisso com a construção do conhecimento.

U ma pesquisa realizada com internos da FENF / UERJ verificou que a pedagogia problematizadora favoreceu uma postura crítica e reflexiva, 0 que fomentou mudanças positivas nas relações interpessoais dos alunos com os pacientes, com a equipe de saúde e com os docentes, instrumentalizando-os para uma vida profissional pautada na ética ${ }^{(13)}$. Outro estudo realizado com egressos da mesma instituição demonstrou que o perfil profissional apreendido reflete 0 desejado pel 0 atual currículo: o enfermeiro crítico e reflexivo, atendendo os desafios impostos pelo mundo do trabalho(14).

Por esse motivo, a terminologia "processo de ensinagem" foi amplamente utilizada nesse estudo, sendo definida como sendo uma prática social a ser efetivada por professores e al unos e que abrange duas ações simultâneas: ensinar e apreender. A mbas ocorrem num processo de parceria deliberada e consciente entre os agentes, visando o enfrentamento na construção do conhecimento, e em decorrência das ações que foram efetuadas no âmbito da sala de aula e também das que aconteceram fora deste espaço ${ }^{(15)}$.

Nesse contexto, no processo de ensinagem torna-se essencial a aprendizagem discente, sendo 0 enfrentamento do conhecimento uma parceria entre professor e alunos.

0 educador tem como papel fundamental contribuir positivamente na construção do conhecimento discente, tornando-o responsável por sua formação profissional. N o entanto, a formação profissional envolve sentimentos diversos, como frustrações, medos e desejos, e o educador faz-se necessário na condução desse processo ${ }^{(9)}$.

A mediação docente é indispensável em todas as etapas da construção do conhecimento discente, levando os alunos ao desenvolvimento de processos de mobilização, construção e elaboração da síntese do conhecimento. Ele prepara e dirige as atividades e as ações necessárias, bem como as estratégias de ensinagem, que consistem em méto- dos, técnicas e meios de construção de conhecimento ${ }^{(15)}$.

Comprovadamente essencial à condução docente no processo de ensinagem, a temática "drogas" não deve ser negligenciada, uma vez que, por detrás dela, há um verdadeiro conjunto de situações econômicas, sociais, familiares e individuais e para lidar com esses problemas é preciso ter a clareza dessa complexidade.

Para lidar com uma temática que se configura como multifacetada e multicausal "[ ...] o enfermeiro deve estar instrumentalizado para oferecer uma assistência apropriada, abrangendo habilidades teóricas e práticas, incluindo tipos de intervenção, técnicas de motivação para mudanças de comportamento do uso de substâncias psicoativas, conhecimento das inter ações das substâncias, desenvolvimento de prog ramas, pesquisas e aval iação dos resultados"(16). D essa forma, só a condução apropriada do docente viabiliza o desenvolvimento dessas habilidades.

Cabe ao enfermeiro desenvolver postura crítica-reflexiva que possibilite o acompanhamento dinâmico da realidade É o educador que desenvolve essa postura, principalmente na prática, onde sintetiza o conhecimento adquirido no decorrer da graduação $0^{(15)}$. Sem ele, o discente não consegue lançar um ol har crítico sobre a prática, até porque está interessado em aplicar seus conhecimentos teóricos e executar técnicas pertinentes à equipe de enfermagem. Q uando consegue, não sintetiza o aprendizado, não construindo de fato conhecimento.

Nesse sentido, o profissional constrói o seu conhecimento através da vivência das situações práticas, objetivando a formação de um perfil de profissional reflexivo, autônomo e competente.

\section{METODOLOGIA}

Trata-se de uma pesquisa descritiva com abordagem qual itativa, desenvolvida com estudantes de graduação da FENF / U ERJ, situada à Boulevard 28 de Setembro, no 157, bairro de Vila I sabel, na cidade do Rio de Janeiro.

A F aculdade possui um corpo docente de 89 professores atuantes na graduação e aproximadamente 360 discentes inscritos entre o primeiro e 0 nono período. Os sujeitos do estudo foram 19 acadêmicos de enfermagem dos três últimos períodos. Tais períodos foram selecionados porque já obtiveram os conhecimentos teóricos programados 
pelo curso de graduação, uma vez que os dois últimos períodos consistem em aprendizagem no modelo de internato, período transitório entre aluno e profissional. No internato o discente aplica os conhecimentos adquiridos no decorrer da graduação sob a supervisão de um enfermeiro. D essa forma, o critério definidor do traço comum foi o fato de tratar-se de discentes que já tenham iniciado o inter nato ou que estejam na iminência de começá-lo.

Os dados foram coletados nos meses de dezembro de 2008 e janeiro de 2009, mediante a utilização da técnica do grupo focal, uma espécie de entrevista de grupo que consiste em se apoiar na inter ação entre seus participantes para colher dados em torno de um tema de interesse coletivo ${ }^{(17)}$.

Entendemos que um ambiente permissivo facilita a expressão de emoções, os comentários de um sujeito podem fazer emergir a opinião de outros ${ }^{(17)}$, o que é característico de grupos focais como aplicados no presente estudo. Por esse motivo, optamos por não solicitar que se identificassem antes de cada pronunciamento no ambiente do grupo. D esse modo, neste estudo, optamos por não identificar os depoimentos citados como sendo individualizados, mas sim consider ados como depoimentos emanados do grupo.

Por se tratar de pesquisa que envolve seres humanos, foram observados os aspectos éticos disciplinados pela Resolução 196/ 96 do Consel ho Nacional de Saúde(18). 0 projeto foi aprovado pela Comissão de Ética em Pesquisa da U ERJ, de acordo com o protocolo no 029.3.2008. A ntes do início da coleta de dados, os estudantes assinaram o T ermo de Consentimento Livre e E sclar ecido, sendoIhes garantido 0 anonimato e confidencialidade, o sigilo das respostas evitando-se julgamentos.

Os sujeitos receberam previamente um convite formal, respeitando a grade de horários, a fim de facilitar a presença de cada grupo. T rês grupos focais foram realizados, um para cada período de graduação, com uma média de sete participantes. 0 tamanho do grupo facilitou o desenvolvimento do estudo, uma vez que o assunto abordado é a realidade cotidiana del es e todos quiseram manifestar suas opiniões e sugestões.

Ressal ta-se a dificul dade de agendamento com os sujeitos, que se encontram subdivididos em grupos durante 0 internato, em hospitais e centros municipais de saúde do Rio de J aneiro. Já a dificuldade com o grupo referente ao sétimo período foi por estar na fase de conclusão de período, associa- do ao período recente de greve que vivenciaram, atrasando seu término.

A discussão foi conduzida por uma moderadora que utilizou dinâmicas de grupo a fim de compreender os sentimentos expressos pelos participantes. D ois outros participantes exerceram função de observadores. No primeiro grupo, a moderadora foi uma mestre em enfermagem com experiência na condução de grupos focais que, nesse momento, realizou o treinamento da autora do estudo. D essa forma, os outros grupos focais foram mediados pela autora.

A análise dos depoimentos obtidos pela técnica do grupo focal e as anotações no diário de campo foram tratados a partir das concepções de análise de conteúdo, que consiste em um "conjunto de procedimentos, sistemáticos e objetivos de descrição do conteúdo técnicas de análise das comunicações, visando obter, por procedimentos objetivos e sistemáticos de descrição do conteúdo das mensagens, indicadores (quantitativos ou não) que permitam a inferência de conhecimentos relativos às condições de produção e recepção destas mensagens" ${ }^{\prime \prime}(19)$.

M ediante a anál ise dos dados surgiu a discussão em torno das experiências vivenciadas pelos discentes, resultando na elaboração desse artigo.

\section{RESULTADOS E DISCUSSÃO}

$\mathrm{N}$ a análise dos dados, a condução docente prevaleceu sobre os outros temas que surgiram, uma vez que abrange todas as fases do processo de ensinagem.

Os resultados evidenciaram a dificuldade dos discentes no enfrentamento da realidade, decorrente do contraste entre a teoria e a prática. I nfere-se que tal dificuldade manifestada pelos alunos decorra da condução docente inapropriada.

Como o educador é imprescindível na construção do conhecimento, a contradição transparece quando não há docente acompanhando o al uno na prática, apenas o preceptor local. D essa forma os discentes se deparam com o despreparo dos profissionais de saúde em relação aos pacientes usuários de drogas, como relatado abaixo:

U m paciente que ficou internado dois meses em outro hospital, veio pra cá. 0 relato dele é de que parou há três anos e, na evolução, ainda tem descrição de síndrome de abstinência. 
M ediante a condução do professor, tal situação serviria de instrumento para a construção do conhecimento, que implica o exercício da curiosidade, na capacidade crítica de observar e anal isar o objeto, comparando-o com suas percepções e conhecimentos anteriores ${ }^{(10)}$.

O utro ponto que merece atenção do docenteéa violência da equipe de saúde com pacientes usuários de drogas, encarada com naturalidade no campo de estágio, como aponta as seguintes observações:

0 paciente tinha conseguido se soltar. Quando foi dar conta elejá estava em pée aí o cara falou assim: "Volta pra cama já". Aí amarrou o cara.

E letava amar rado, não era assi m, agitado... el eestava tranqüilo, não estava delirando.

As experiências vivenciadas só reforçam a idéia de que o discente, menos maduro que o professor, necessita da condução deste no processo, mas precisa participar del eativamente, a aprendizagem é uma ação intencional, direcionada e deliberada por parte do aluno, exigindo esforços conjuntos com o professor para o domínio do conhecimento ${ }^{(15)}$. Felizmente os discentes construíram de fato conhecimento durante a graduação em relação à humanização, direitos e deveres da equipe de enfermagem entre outros, independente da condição clínica do paciente. I sso se reflete quando demonstram sua indignação ao reproduzirem a fala de uma das preceptoras do hospital:

A enfer meira aqui... estava compartil hando a rotina de trabalho dela com a gente. $E$ ela falou assim, que che gam aqueles capetas daqueles bêbados na emergência. 0 que é que ela faz... brinca com eles. Por exemplo, uma sonda de 20. E la falou que amarra todos eles.

E ela acrescenta:

Se eles tiverem puxando muito papo, amarro a boca também.

D essa forma, os acadêmicos de enfermagem ficam à mercê de reproduzir práticas vivenciadas incorretas e condutas que confrontam a ética e os deveres do profissional enfer meiro. $N$ ão necessariamente essas práticas serão incorporadas em seu cotidiano, uma vez que existe distinção entre infor mação e conhecimento. A inda assim eles manifestam tal preocupação:
A gente vê os profissionais... e aí 0 aluno que tem que fazer estágio acaba reproduzindo isso... puramente por desconhecimento. 0 que a gente tem é a oportunidade de ver como éa realidade da assistência.

A pesar de nem toda experiência resultar em aprendizagens automáticas, tal afirmação ampara nossa percepção quando, nas falas dos discentes, verificamos que eles reconhecem as práticas inadequadas como incabíveis e até desumanas. Reforça-se, assim, a importância do papel do educador, de não apenas ensinar os conteúdos, mas também ensinar certo ${ }^{(9)}$.

Ressalta-se que, dentre os usuários de drogas, os al coolistas são bastante neglig enciados pel a equipe de saúde. Em outros relatos dos discentes transparece o queéensinado como correto nas práticas vivenciadas por eles:

Aí 0 que você escuta né, é a questão da equipe: "A $h, 0$ cara éalcoólatra, tem queficar preso, porque ele vai te agredir".

Porque que ele tá amarrado? A justificativa: ele tá amarrado porque ele é alcoolista, ele é perigoso, né? P orque el e pode entrar em abstinência, ele pode te atacar. Ai você realmente se assusta, né? E você vai acreditar porquevocênão teve conhecimento para sepreparar sobre isso.

Os discentes apontam a falta de conhecimento para lidar com a situação do alcoolista, sinalizando que a abordagem do fenômeno das drogas durante a graduação não foi efetiva. A lguns estudos defendem a mobilização discente, por meio do conhecimento, a fim de estarem alertas quanto aos efeitos e riscos das drogas, inclusive as lícitas (20).

A pesar da instituição de ensino estudada ter como proposta a educação problematizadora, os acadêmicos não foram sensibilizados para agir e interagir em face do uso e abuso de drogas, ressaltando a necessidade da abordagem do tema nos cursos de graduação, capacitando os futuros profissionais. Desse modo registramos a necessidade da abordagem da temática na graduação de enfermagem, sensibilizando os futuros profissionais.

\section{CONCLUSÕES}

Os resultados evidenciaram que o enfrentamento da realidade frente ao fenômeno das drogas pelos discentes reflete a dicotomia entre teoria e 
prática, ficando estes à mercê de uma reprodução de práticas vivenciadas consideradas incorretas juntamente com condutas que confrontam a ética e os deveres do profissional enfermeiro. Ao estudante é possibilitada, no entanto, a tomada de decisão quanto a incorporar essas práticas em seu cotidiano.

Como a educação problematizadora adotada permite a troca de conhecimento e, conseqüentemente a construção dele, as experiências vivenciadas pel os discentes favorecem a metodologia quando bem explorada pelo docente. A ssociado a isso, 0 processo de ensinagem é aplicado auxiliando nessa construção. N esse sentido, faz-se necessária a presença docente, que interage com o educando e 0 orienta em sua prática cotidiana, contribuindo para a construção do conhecimento sobre o fenômeno das drogas.

$M$ ediante a realidade da sociedade contemporânea, onde o fenômeno das drogas se apresenta como problema de saúde pública, as instituições de ensino devem otimizar a utilização do processo de ensinagem, tor nando o profissional enfermeiro um agente transformador da sociedade. D esse modo, a for mação profissional dos enfermeiros em relação ao fenômeno das drogas torna-se essencial à medida que precisam conduzir tais situações no seu cotidiano. Isso pode ser possível mediante a aplicação do processo de ensinagem para a construção do conhecimento sobre drogas.

\section{REFERÊNCIAS}

1 Santos VOG. A construção do conhecimento acerca do fenômeno das drogas: desafios no ensino crítico e problematizador [ dissertação] . Rio de aneiro: Faculdade de E nfer magem, $U$ niversidade do E stado do R io de Janeiro; 2010.

2 Carlini EA, N appo AS, G alduróz J CF, N oto A R. D rogas psicotrópicas: o que são e como agem. Rev IM ESC [ Internet] . 2001 [ citado 2010 maio 31] ;3:9-35. Disponível em: http:/ / www.imesc.sp.gov.br/ pdf/artigo\%201\%20-\%20D ROG A S\%20PSICOT R \%C 3\%93 PICAS\%200\%20QU E \%20S\%C 3\%830\% 20E \%20 COM 0\%20A GEM.pdf.

3 Organização M undial de Saúde. D ados sobre o fenômeno das drogas no mundo [ I nter net] . Rio de Janeiro; 2008 [ citado 2010 maio 31] . Disponível em: http:// www.who.int/ substance_abuse/ facts/global_burden/ en/ index.html.
4 L opes G T, Lemos BKJ, Lima H B, Cordeiro BRC, Lima LSV. Concepções de acadêmicos de enfer magem sobre usuários de drogas. Rev Bras E nferm. 2009;62(5):51823.

5 G onçalves SSPM , T avares CM M . A tuação do enfermeiro na atenção ao usuário de álcool e outras drogas nos serviços extrahospitalares. Esc Anna Nery Rev Enferm. 2007;11(5):586-92.

6 Carraro TE, Rassool GH, Luis M AV. A formação do enfermeiro e o fenômeno das drogas no sul do Brasil: atitudes e crenças dos estudantes de enfer magem sobre o cuidado. Rev L atino-A m E nfermagem. 2005;13(n esp):863-71.

7 Spricigo JS, A lencastre M B. 0 enfermeiro da unidade básica de saúde e o usuário de drogas: um estudo em Biguaçú - SC. Rev Latino-Am E nfermagem. 2004;12 (5):427-32.

8 Belei RA, G imeniz-Paschoal AS, N ascimento E M , N ery $A C B$. Profissionalização dos professores universitários: raízes históricas, problemas atuais. Rev Bras Estud Pedagog. 2006;87(217):401-10.

9 F reire P. Pedagogia da autonomia: saber es necessários à prática educativa. $2^{\mathrm{a}}$ ed. R io de Janeiro: Paz e T erra; 1997.

10 M aia CM , Scheibel M F. Didática: organização do trabalho pedagógico. Curitiba: IESD E; 2008.

110 pitz SP, M artins JT, T elles F ilho PCP, Silva AE BC, T eixeira T CA . $O$ currículo integrado na graduação em enfer magem: entre 0 ethos tradicional e o de ruptura. Rev G aúcha E nferm. 2008;29(3):314-9.

12 Oliveira M AC, Veríssimo M LOR, P üschel VA, Riesco $M L G$. D esafios da for mação em enfer magem no Brasil: proposta curricular da E EU SP para o bacharelado em enfermagem. Rev Esc E nferm U SP. 2007;41(n esp):820-5.

13 Souza NVD O, Silva M F, Cruz EJER, Santos M S. Pe dagogia problematizadora: relacionamento interpessoal dos internos de enfermagem no contexto hospitalar. Rev Enferm UERJ. 2007;15(1):27-32.

14 Souza N VD 0, Correia L M , Pereira AM, Rodrigues BM RD, M acedo A, Pena DA, et al. Enfermeiro e a teoria crítica da educação: sua inser ção no mundo do trabalho. Rev Enferm UERJ. 2006;14(4):506-11.

15 A nastasiou LG C, A Ives LP. Processos de ensinagem na universidade: pressupostos par a as estr atégias de trabal ho em aula. 8a ed. Joinville: U niville; 2009. 
16 Pillon SC, Laranjeira RR. Formal education and nurses' attitudes towards alcohol and alcoholism in a Brazilian sample. São Paulo M ed J. 2005;123(5):17580.

17 Carlini-Cotrim B. Potencialidades da técnica qualitativa grupo focal em investigações sobre abuso de substâncias. Rev Saúde Pública. 1996;30(4):285-93.

18 M inistério da Saúde (BR), Conselho N acional de Saúde, Comitê N acional de Ética em Pesquisa em Seres
H umanos. Resolução 196, de 10 de outubro de 1996: diretrizes e normas regulamentadoras de pesquisa envolvendo seres humanos. Brasília (DF ); 1996.

19 Bardin L. A nálise de conteúdo. 3ạ ed. Lisboa: E dições 70; 2004.

20 Zeferino M T, Santos VEP, Radünz V, Carraro TE, F rello AT. Enfer meiros e uso abusivo de drogas: comprometendo o cuidado de si e do outro. Rev Enferm UERJ. 2006;14(5):599-606.

\section{Endereço do autor / Dirección del autor /}

\section{Author's address:}

Octavio M uniz da Costa Vargens

Rua Constante Ramos 136, ap. 503, Copacabana

22051-012, Rio de Janeiro, RJ

E-mail: omcvargens@uol.com.br
Recebido em: 18/ 12/ 2009

A provado em: 09/ 03/ 2010 